\title{
Prognostic ability of EndoPredict compared to research-based versions of the PAM50 risk of recurrence (ROR) scores in node- positive, estrogen receptor-positive, and HER2-negative breast cancer. A GEICAM/9906 sub-study
}

\author{
Miguel Martin ${ }^{1} \cdot$ Jan C. Brase ${ }^{2} \cdot$ Amparo Ruiz $^{6} \cdot$ Aleix Prat $^{7} \cdot$ Ralf Kronenwett $^{2}$ • \\ Lourdes Calvo $^{8} \cdot$ Christoph Petry $^{2} \cdot$ Philip S. Bernard $^{9} \cdot$ Manuel Ruiz-Borrego ${ }^{10}$. \\ Karsten E. Weber ${ }^{2}$. César A. Rodriguez ${ }^{11}$ - Isabel M. Alvarez ${ }^{12}$. Miguel A. Segui ${ }^{13}$. \\ Charles M. Perou ${ }^{3,4,5}$ - Maribel Casas ${ }^{14}$ - Eva Carrasco $^{14}$ - Rosalía Caballero $^{14}$. \\ Alvaro Rodriguez-Lescure ${ }^{15}$
}

Received: 30 December 2015/ Accepted: 16 February 2016/Published online: 24 February 2016

(C) The Author(s) 2016. This article is published with open access at Springerlink.com

\begin{abstract}
There are several prognostic multigene-based tests for managing breast cancer (BC), but limited data comparing them in the same cohort. We compared the prognostic performance of the EndoPredict (EP) test (standardized for pathology laboratory) with the researchbased PAM50 non-standardized qRT-PCR assay in nodepositive estrogen receptor-positive $(\mathrm{ER}+)$ and HER2-
\end{abstract}

Electronic supplementary material The online version of this article (doi:10.1007/s10549-016-3725-z) contains supplementary material, which is available to authorized users.

Miguel Martin

mmartin@geicam.org

1 Department of Medical Oncology, Instituto de Investigación Sanitaria Gregorio Marañon, Universidad Complutente de Madrid, Calle Maiquez 7, Madrid, Spain

2 Sividon Diagnostics $\mathrm{GmbH}$, Cologne, Germany

3 Lineberger Comprehensive Cancer Center, University of North Carolina, Chapel Hill, NC, USA

4 Department of Genetics, University of North Carolina, Chapel Hill, NC, USA

5 Department of Pathology \& Laboratory Medicine, University of North Carolina, Chapel Hill, NC, USA

6 Department of Medical Oncology, Valencian Institute of Oncology (IVO), Valencia, Spain

7 Translational Genomics Group, Vall d'Hebron Institute of Oncology (VHIO), Barcelona, Spain

8 Department of Medical Oncology, A Coruña University Hospital Complex, A Coruña, Spain

9 Solid Tumor Molecular Diagnostics Laboratory, ARUP Laboratories, Utah, USA negative (HER2-) BC patients receiving adjuvant chemotherapy followed by endocrine therapy (ET) in the GEICAM/9906 trial. EP and PAM50 risk of recurrence (ROR) scores [based on subtype (ROR-S) and on subtype and proliferation (ROR-P)] were compared in $536 \mathrm{ER}+/$ HER2 - patients. Scores combined with clinical information were evaluated: ROR-T (ROR-S, tumor size), RORPT (ROR-P, tumor size), and EPclin (EP, tumor size, nodal status). Patients were assigned to risk-categories according to prespecified cutoffs. Distant metastasis-free survival

10 Department of Medical Oncology, Virgen del Rocio University Hospital, Seville, Spain

11 Department of Medical Oncology, Salamanca University Hospital-IBSAL, Salamanca, Spain

12 Department of Medical Oncology, Donostia University Hospital, Donostia, Spain

13 Department of Medical Oncology, Parc Tauli University Hospital, Sabadell, Spain

14 Spanish Breast Cancer Research Group (GEICAM), Madrid, Spain

15 Department of Medical Oncology, Elche University General Hospital, Elche, Spain 
(MFS) was analyzed by Kaplan-Meier. ROR-S, ROR-P, and EP scores identified a low-risk group with a relative better outcome (10-year MFS: ROR-S $87 \%$; ROR-P $89 \%$; EP $93 \%)$. There was no significant difference between tests. Predictors including clinical information showed superior prognostic performance compared to molecular scores alone (10-year MFS, low-risk group: ROR-T $88 \%$; ROR-PT $92 \%$; EPclin $100 \%$ ). The EPclin-based risk stratification achieved a significantly improved prediction of MFS compared to ROR-T, but not ROR-PT. All signatures added prognostic information to common clinical parameters. EPclin provided independent prognostic information beyond ROR-T and ROR-PT. ROR and EP can reliably predict risk of distant metastasis in node-positive ER+/HER2 - BC patients treated with chemotherapy and ET. Addition of clinical parameters into risk scores improves their prognostic ability.

Keywords Breast cancer · PAM50 - EndoPredict · Chemotherapy · Prognosis

$\begin{array}{ll}\text { Abbreviations } \\ \text { BC } & \text { Breast cancer } \\ \text { ET } & \text { Endocrine therapy } \\ \text { EP } & \text { EndoPredict score } \\ \text { FEC } & \text { 5-Fluorouracil, epirubicin, and } \\ & \text { cyclophosphamide } \\ \text { FEC-P } & \text { FEC followed by paclitaxel } \\ \text { FFPE } & \text { Formalin-fixed paraffin embedded } \\ \text { MFS } & \text { Metastasis-free survival } \\ \text { ROR } & \text { Risk of recurrence } \\ \text { ROR-S } & \text { ROR score based on subtype information } \\ \text { ROR-P } & \text { ROR based on subtype and proliferation } \\ \text { ROR-T } & \text { ROR based on subtype and tumor size } \\ \text { ROR-PT } & \text { ROR based on subtype, proliferation, and } \\ & \text { tumor size } \\ \text { vs } & \text { Versus }\end{array}$

\section{Background}

Gene expression tests are new tools to clinically determine the risk of relapse in early-stage breast cancer (BC) [1, 2]. The 21-gene recurrence score (Oncotype DX) and Mammaprint (NKI-70) [3-10] have been shown to impact treatment decisions [11-13]. Novel prognostic tests, such as EndoPredict and PAM50, are also able to predict early, as well as late metastases [14, 15].

EndoPredict is a standardized test for the molecular pathology laboratory and was the first multigene test used in a decentralized setting $[16,17]$. It was established and validated in two independent clinical validation studies (ABCSG6 and ABCSG8) involving patients with ER+/ HER2 - BC treated with adjuvant endocrine therapy (ET) only [18]. EndoPredict provides prognostic information beyond all common clinicopathological parameters [18] and clinical guidelines [19]. The molecular information (EP score) is further combined with tumor size and nodal status resulting in the EPclin score.

The PAM50 assay is an optimized gene set used to identify intrinsic subtypes and predict the Risk Of Recurrence $(\mathrm{ROR})$ at 10 years $[20,21]$. The ROR score was developed in a microarray-based cohort of node-negative, untreated BC patients [6, 20]. Four versions of ROR exist in the research setting: ROR based on subtype information (ROR-S), ROR-S with proliferation (ROR-P), ROR-S with tumor size (ROR-T), and ROR-P with tumor size (RORPT) [20, 21]. The minimum ROR score of all Luminal B scores was assigned as the low-risk threshold for each model and the maximum ROR score of all Luminal A scores as the high-risk threshold [21].

The inclusion of established clinicopathological risk factors in ROR and EP scores, such as tumor size (ROR-T, ROR-PT, and EPclin) and nodal status (EPclin), increases their predictive performance [18-21]. EndoPredict and research-based PAM50 were evaluated independently in the GEICAM/9906 trial [22-25]. We compared the prognostic performance of the EP test with the research-based, non-standardized PAM50 assay in node-positive, ER+/ HER2- BC patients treated with adjuvant chemotherapy followed by ET.

\section{Patients and methods}

\section{Patients and tumor samples}

Patients in this study participated in the GEICAM/9906 trial, a randomized phase III trial that compared adjuvant chemotherapy regimen of 5-fluorouracil, epirubicin, and cyclophosphamide (FEC) with FEC followed by weekly paclitaxel (FEC-P), and then followed by 5-year hormonal therapy (tamoxifen, aromatase inhibitors or both) in 1246 women with lymph node-positive disease [26]. This trial was performed in accordance with the Declaration of Helsinki, approved by the ethics committees at all participating institutions (see Supplementary Table 1S) and the Spanish Health Authority, and registered at www.clin icaltrials.gov (NCT00129922). Patients provided their written informed consent for therapy randomization and molecular analyses. Patients whose tumors were ER+/ HER2 - according to a central review by qRT-PCR and consented to genomic analysis were eligible. 
Formalin-fixed paraffin-embedded (FFPE) tumor blocks used to compare PAM50 and EP scores were collected at the time of surgery.

\section{EndoPredict gene expression analysis}

RNA extraction and gene expression analysis for identifying the ER+/HER2 - subgroup and performing the EndoPredict have been recently described. Briefly, total RNA was extracted from one 5- $\mu \mathrm{m}$ whole FFPE tissue section using a silica bead-based, fully automated isolation method (Tissue Preparation System, VERSANT Tissue Preparation Reagents, Siemens Healthcare Diagnostics) [27].

To identify patients with ER+/HER2 - tumors, ESR1 and ERBB2 gene expression levels were analyzed and predefined cut-off levels were applied as recently described. The EP score is based on eight cancer-related genes (BIRC5, UBE2C, DHCR7, RBBP8, IL6ST, AZGP1, MGP, $S T C 2$ ) and three reference genes (CALM2, OAZ1, RPL37A), and measured by qRT-PCR [18].

\section{PAM50-ROR gene expression analysis}

RNA was extracted from two 1-mm FFPE cores as previously described [20]. To determine the research-based versions of the ROR scores and groups, normalized gene expression data obtained from the qRT-PCR platform were gene-median-centered, and the microarray-based PAM50 intrinsic subtype predictor was applied as previously described [20]. Of note, the microarray-based training dataset, from which survival coefficients were derived, is based on patients with node-negative disease that did not receive adjuvant systemic therapy [6]. In addition, ROR thresholds (low and high) consist of subtype distributions along the ROR scores in the training dataset [21].

\section{Statistical analysis}

The ROR and EP scores were calculated blinded to clinical data and sent to the GEICAM study group in Madrid for independent statistical analysis. Only the GEICAM group had access to the combined clinical outcome and gene expression data.

The primary endpoint was distant metastasis-free survival (MFS) estimated using the Kaplan-Meier method. Pearson correlations compared gene signatures. Two-sided log-rank tests were used to compare subgroups. $P$ values $<5 \%$ were considered statistically significant. Each gene signature was added to a model containing common clinical parameters and one other evaluated signature. $\mathrm{C}$-indices were then calculated for the clinical variables and model combinations to estimate the performance of each variable for predicting distant metastasis. Differences were evaluated using the log-likelihood ratio statistic test (for proportional Cox model hazard rates) and the comparison of c-index with resampling (both one-sided tests).

The PAM50 ROR-S, ROR-P, and ROR-T and ROR-PT scores classified patients as low-, intermediate-, and highrisk, using the following pre-defined cut-off values, respectively: ROR-S $(<24 ; 24-53 ;>53)$, ROR-P $(<12$; 12-53; >53), ROR-T (<29; 29-65; >65), PAM50 ROR-PT $(<18 ; 18-65 ;>65)$. Both, EP and EPclin categorized patients into low- (EP score $<5$; EPclin score $<3.3$ ) and high-risk groups (EP score $\geq 5$; EPclin score $\geq 3.3$ ) [18]. The following clinical parameters were used for the analysis: positive nodal status $(1-3 ; 4-10 ;>10)$; tumor size $[\mathrm{cm}$ $(\leq 1 ;>1-\leq 2 ;>2-\leq 5 ;>5)]$; Grade $(1 ; 2 ; 3)$; age; and treatment arm (FEC; FEC-P).

\section{Results}

\section{Patient population}

A total of $566(71 \%)$ of 800 available tumor samples were eligible for evaluation. Tumor samples lacking PAM50 or EndoPredict data were excluded (5\%). Characteristics of the patient cohort included in this study are summarized in Supplementary Table 2S.

\section{Risk categorization}

Patients with ER+/HER2- BC were classified as low-risk in 32,20 , and $25 \%$ of cases based on the ROR-S, ROR-P, and EP scores, respectively (Supplementary Table 3S). All gene signatures identified low-risk groups with a significant better outcome compared to the other risk groups (Fig. 1). The 10-year MFS rates for low-risk groups were 87, 89, and $93 \%$, respectively (Fig. 1). The EPclin low-risk group was smaller (13\%) compared to ROR-T (22\%) and RORPT (19\%) low-risk groups, but had a better, though not statistically significant, 10-year MFS rate (100 vs. 88 vs. $92 \%$, Fig. 1).

\section{Comparing EP versus PAM50 gene signatures}

As continuous variables, EP was significantly correlated with ROR-S ( $r=0.72)$ and ROR-P $(r=0.68)$. Combining the intermediate- and high-risk groups based on ROR-S (ROR-T) and ROR-P (ROR-PT), resulted in a 21 and $20 \%$ discrepancy in patient categorization when comparing EP vs. ROR-S and EP vs. ROR-P classifications, respectively. The MFS of patients with discordant classification were analyzed to compare EP vs. PAM50 risk assignments yielding non-statistical significant differences. However, 
EP

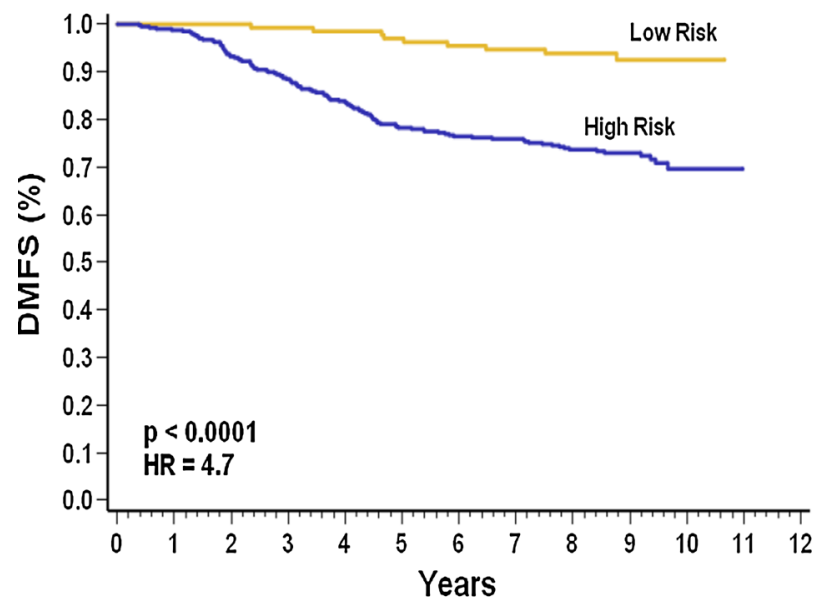

ROR-S

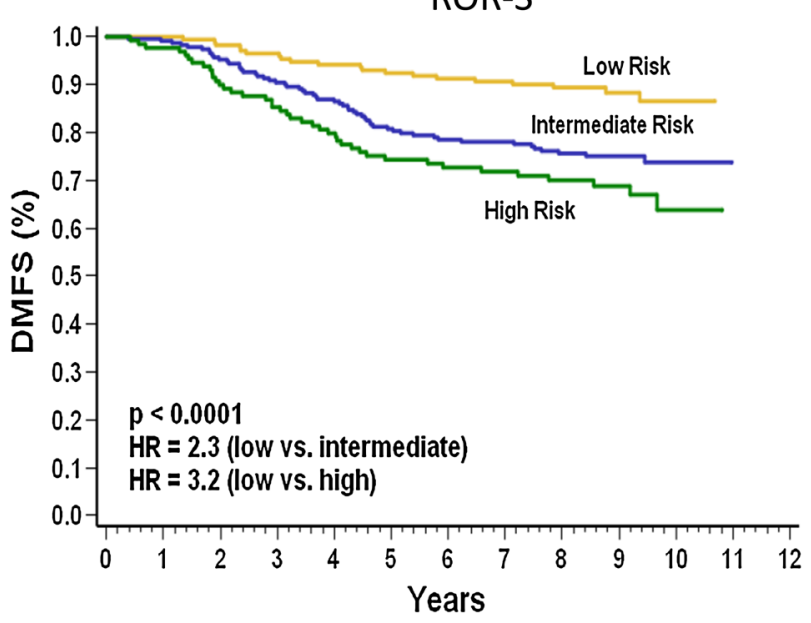

ROR-P

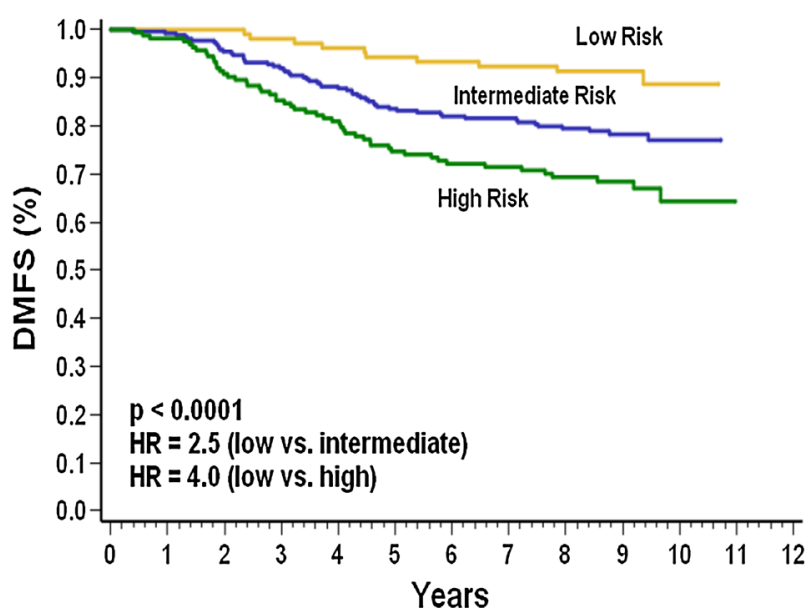

EPclin

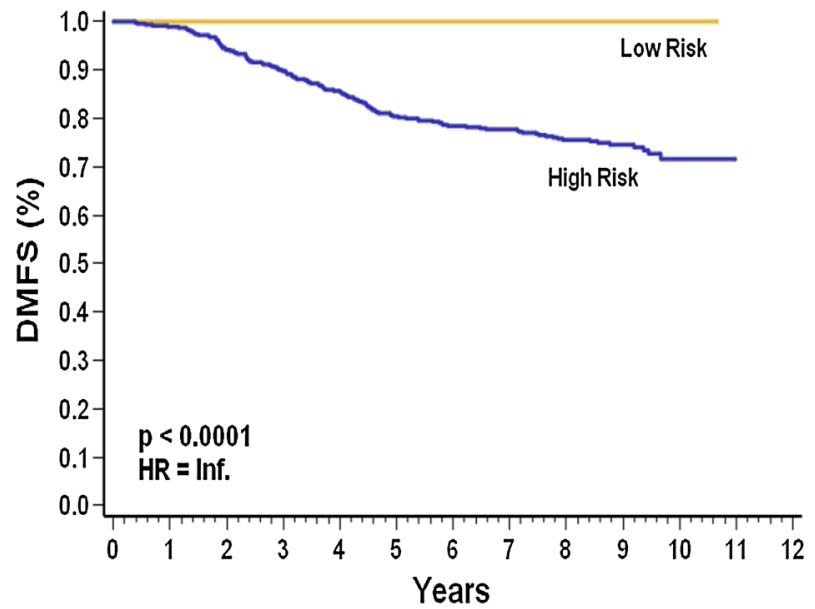

ROR-T
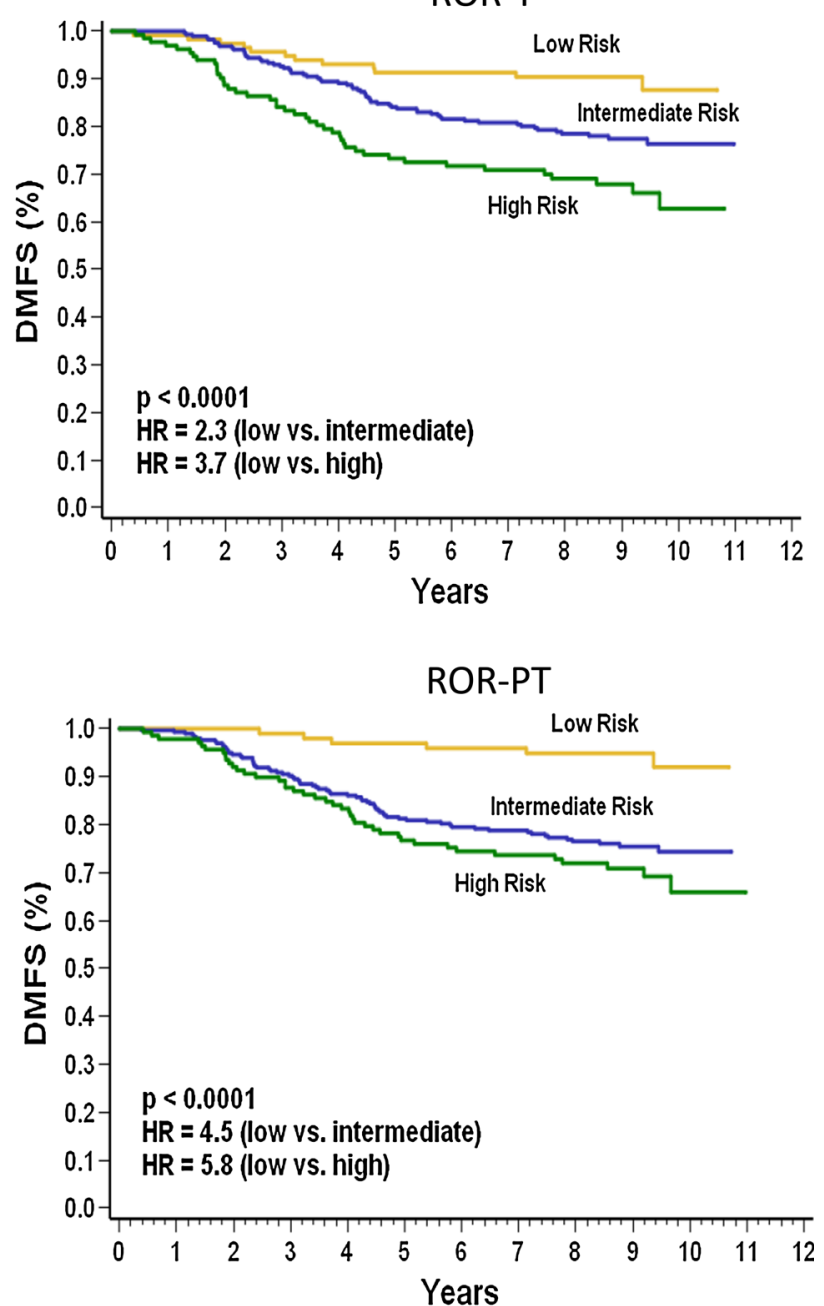
४Fig. 1 Kaplan-Meier curve for metastasis-free survival by EP, RORS, ROR-P, EPclin, ROR-T, and ROR-PT risk groups. PAM50 ROR-S, ROR-P, and ROR-T and ROR-PT scores stratify patients (GEICAM/ 9906, $N=536$ ) in low-risk, intermediate-risk and high-risk. EP and EPclin stratify patients as low-risk for distant recurrence and high-risk groups. Numbers in parentheses indicate the $95 \%$ confidence interval of the hazard ratio. EP EndoPredict score, EPclin EP based on tumor size and nodal status, $R O R$ risk of distant recurrence, $R O R-S$ ROR based on subtype, ROR-P ROR based on subtype and proliferation, $R O R-T$ ROR based on subtype and tumor size, ROR-PT ROR based on subtype, proliferation, and tumor size

EP-based low-risk patients had a better outcome than PAM50-based counterparts (Fig. 2). EPclin-based risk classification proved a superior predictor of MFS than the ROR-T score $(P=0.04)$, but not in comparison to the ROR-PT $(P=0.09)$ (Fig. 2).
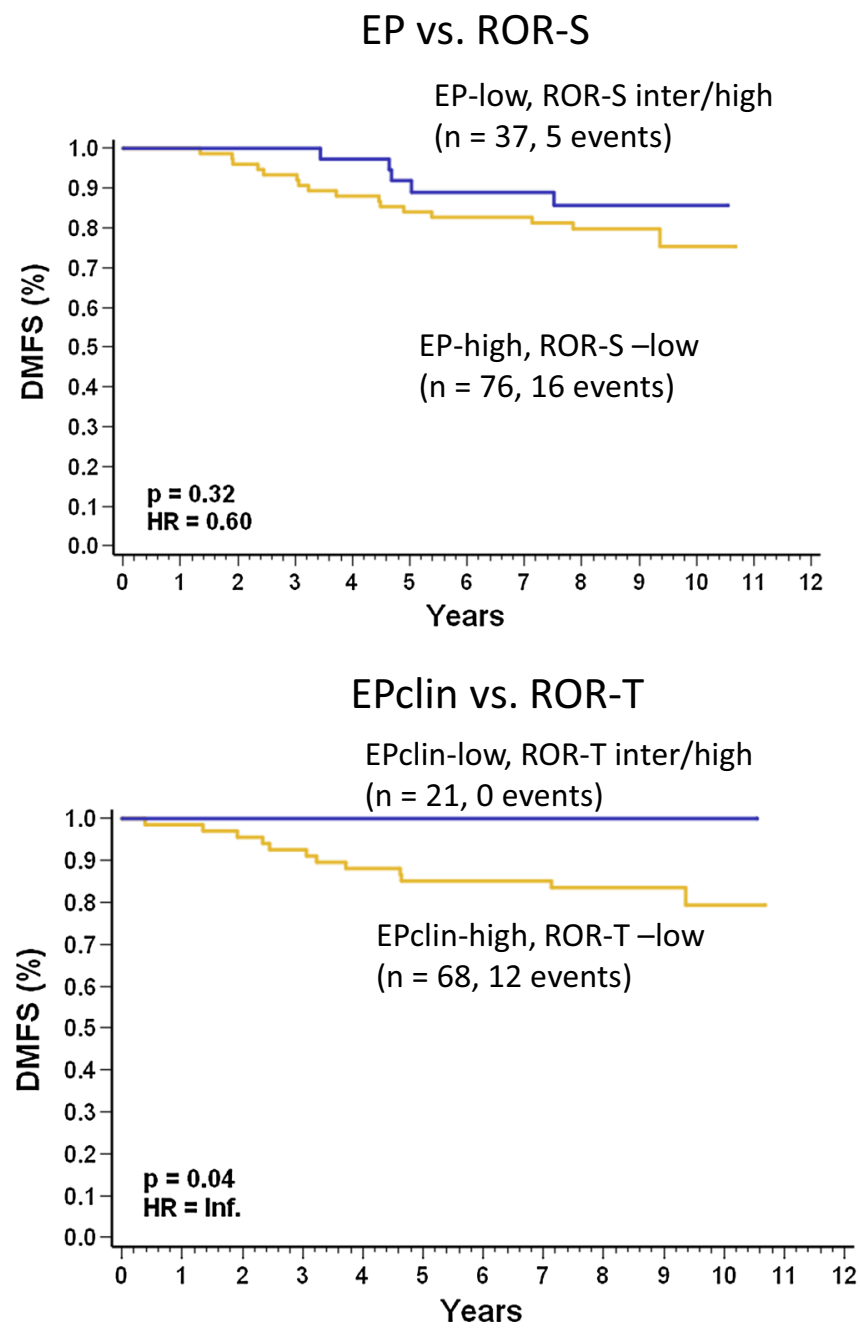

Fig. 2 Kaplan-Meier curves for metastasis-free survival by discordant samples between EP and ROR scores. Kaplan-Meier curves by EP-ROR-S, EP-ROR-P, EPclin-ROR-T, and EPclin-ROR-PT. Numbers in parentheses indicate the $95 \%$ confidence interval of the hazard ratio. EP EndoPredict score, EPclin EP based on tumor size

\section{Prognostic performance of predictors}

Compared to clinical parameters, ROR-S, ROR-P, and EP molecular signatures had substantially higher c-indices (Fig. 3) and added significant prognostic information beyond clinical parameters based on c-index analysis and resampling (data not shown). C-indices for EP, ROR-S, and ROR-P were 0.657, 0.639, and 0.633, respectively. C-indices for EPclin, ROR-T, and ROR-PT were 0.693, 0.649, and 0.644, respectively (Fig. 3).

Based on c-indices and resampling, we determined that EP added prognostic information to ROR-P and clinical parameters, but not to ROR-S. C-index was significantly increased by adding EPclin to models containing clinicopathological parameters and ROR-T $(P<0.001)$, or ROR-
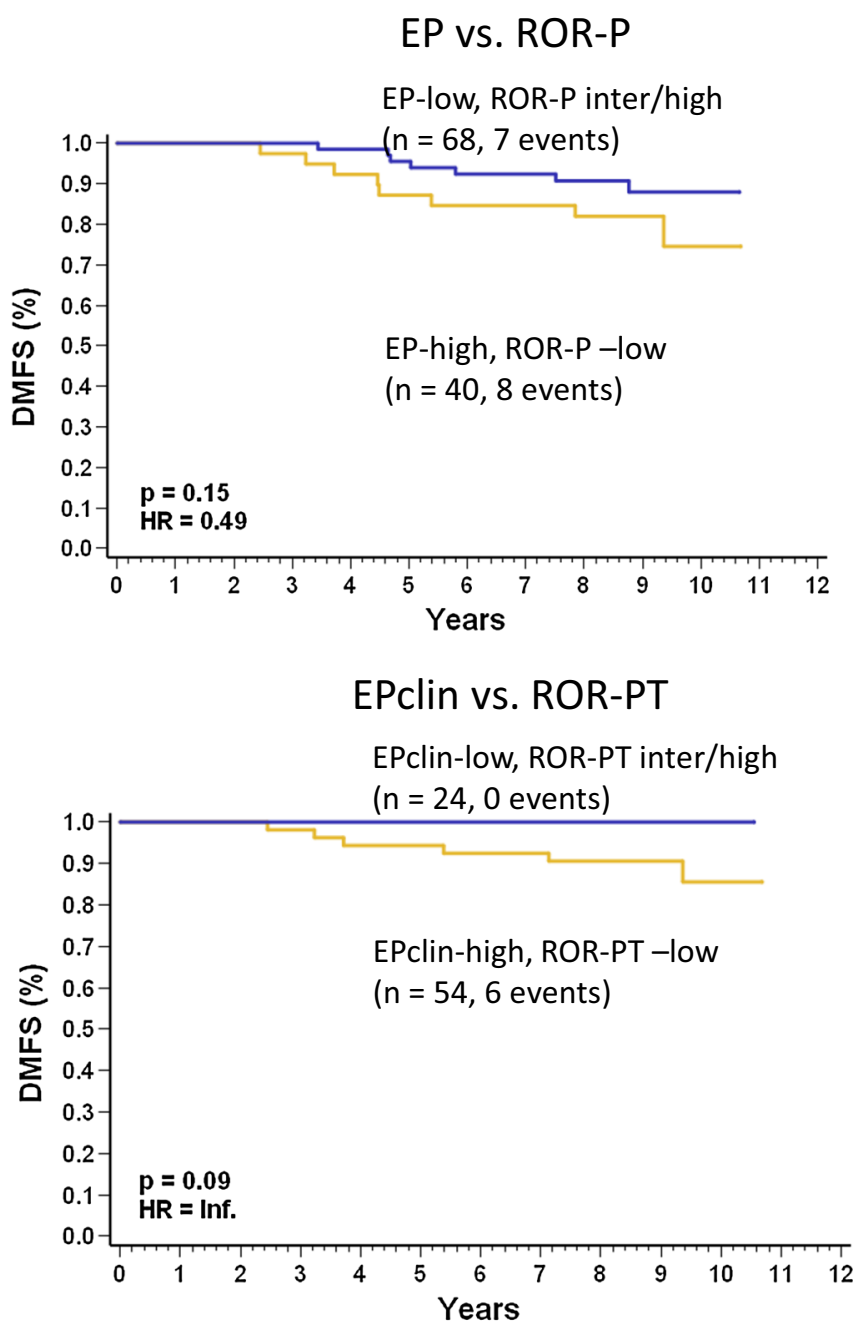

and nodal status, $R O R$ risk of distant recurrence, $R O R-S$ ROR based on subtype, ROR-P ROR based on subtype and proliferation, $R O R-T$ ROR based on subtype and tumor size, ROR-PT ROR based on subtype, proliferation, and tumor size 


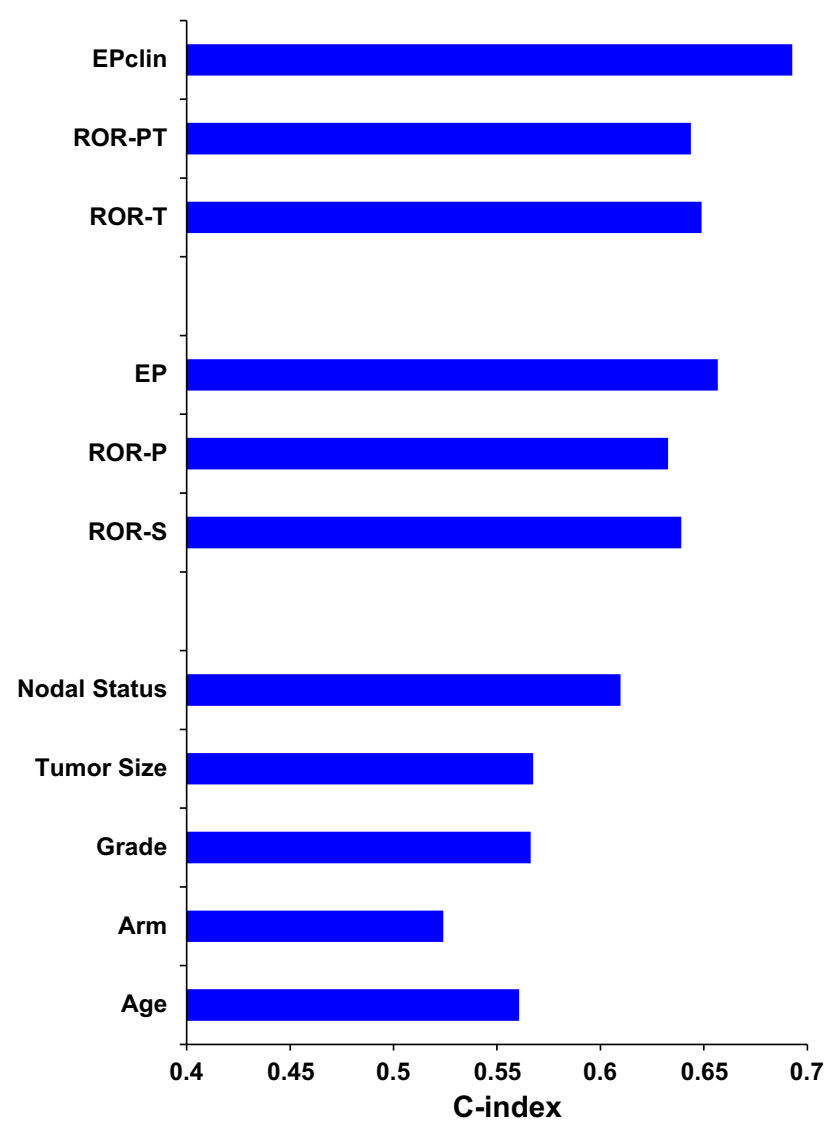

Fig. 3 Distribution of clinical and molecular parameters c-indices. $E P$ EndoPredict score, EPclin EP based on tumor size and nodal status, $R O R$ risk of distant recurrence, $R O R-S$ ROR based on subtype, $R O R-P$ ROR based on subtype and proliferation, ROR-T ROR based on subtype and tumor size, ROR-PT ROR based on subtype, proliferation, and tumor size

PT $(P<0.001)$. ROR-T and ROR-PT failed to add prognostic information to EPclin (Table 1).

\section{Discussion}

We compared the prognostic performance of researchbased and non-standardized versions of PAM50-ROR scores and EndoPredict in ER+/HER2-, node-positive chemotherapy-treated BC patients from the GEICAM/9906 trial.

ROR-S and ROR-P were significantly correlated with EP score, and gene signatures showed agreement in risk classification, indicating that PAM50-ROR and EP scores identify tumors with similar properties. Despite the significant correlation, the discordance rate of $20-21 \%$ can be explained by the tests' inherent characteristics. Our c-index analysis indicated that only EP added significant information to ROR-P. None of the other molecular signatures added information to each other, suggesting that additional predictors would not improve prognostic performance. These findings are concordant with our previous combined analysis of hundreds of signatures and clinical-pathological data for prognostic prediction in ER-positive breast cancer where we observed that not much more prognostic power was obtained by including hundreds of signatures into a single model beyond the power contained within a welldeveloped individual signature when combined with clinical variables [28].

The PAM50-based ROR-T and ROR-PT scores include tumor size, whereas the EPclin score considers nodal status and tumor size, as part of the risk prediction algorithm. Similar to the research-based version, a ROR-PT score weighted for tumor size and proliferation was used to validate the standardized version of PAM50 assay in the ATAC and ABCSG8 trials. In our analysis, all hybrid scores contributed to identifying low-risk groups for distant metastasis, although number of patients and events differed across score categories. The EPclin low-risk group was smaller than the ROR-T and ROR-PT ones and showed no distant-metastatic events. EPclin had been established in a node-positive/node-negative cohort and the predefined cutoff level consequently classified more patients as high-risk in the node-positive GEICAM/9906 trial. In contrast, the research-based versions of ROR-T and ROR-PT scores were derived in a systemically untreated node-negative BC cohort, and thresholds were based on subtype distribution and not actual survival outcomes; therefore, the number of low-risk cases with distant-metastatic events was higher, as reflected by an MFS of 87-92\% in low-risk groups.

Kaplan-Meier analysis of discordant cases, c-index analysis, and log-likelihood tests showed that the EPclinbased risk classification provided independent prognostic information to the ROR-T and ROR-PT scores. The improved performance of the EPclin score over pure molecular scores may be partially explained by the inclusion of nodal status, one of the strongest single prognostic factors, in the EPclin score, but which is not included in any of the other models tested. EndoPredict validation studies demonstrated that molecular EP score, tumor size, and nodal status were the only independent prognostic parameters [18]. Hybrid scores' superior performance compared to their molecular counterparts supports the recommendation of the Evaluation of Genomic Application in Practice and Prevention working group to integrate clinicopathological factors into gene expression tests [29] rather than relying on pure RNA-based molecular scores.

To the best of our knowledge, our study reports the first direct comparison of EndoPredict and a research-based version of the PAM50 assay. Earlier comparisons of multigene signatures suggested similar prognostic performances [30, 31]. Recently, the transATAC study, the first 
Table 1 Additional prognostic information-GEICAM/9906

\begin{tabular}{lllll}
\hline & $\begin{array}{l}\text { ROR-S adds Information to } \\
\text { EndoPredict }\end{array}$ & $\begin{array}{l}\text { ROR-P adds information to } \\
\text { EndoPredict }\end{array}$ & $\begin{array}{l}\text { EndoPredict adds } \\
\text { information to ROR-S }\end{array}$ & $\begin{array}{l}\text { EndoPredict adds } \\
\text { information to ROR-P }\end{array}$ \\
\hline Molecular signature & ROR-S-EP & ROR-P-EP & EP-ROR-S & EP-ROR-P \\
C-index, resampling & $P=0.1455$ & $P=0.1292$ & $P=0.0557$ & $P=0.0194$ \\
Log-likelihood & $(P=0.08844)^{\mathrm{a}}$ & $(P=0.09829)^{\mathrm{a}}$ & $(P=0.05750)^{\mathrm{a}}$ & $(P=0.03162)^{\mathrm{a}}$ \\
Hybrid scores & ROR-T-EPclin & ROR-PT-EPclin & EPclin-ROR-T & EPclin-ROR-PT \\
C-index, resampling & $P=0.4786$ & $P=0.5669$ & $P<0.001$ & $P<0.001$ \\
Log-likelihood & $P=0.406$ & $P=0.3181$ & $P<0.001$ & $P<0.001$ \\
\hline
\end{tabular}

$E P$ EndoPredict score, EPclin EP based on tumor size and nodal status, ROR risk of distant recurrence, ROR-S ROR based on subtype, ROR$P$ ROR based on subtype and proliferation, $R O R-T$ ROR based on subtype and tumor size, $R O R-P T$ ROR based on subtype, proliferation, and tumor size

${ }^{a}$ Hazard ratios are not proportional

large phase III study comparing different standardized gene expression-based biomarkers in the same patient cohort [32], compared the standardized and clinically validated version of PAM50 assay, developed under the nCounter system (Nanostring Technologies), with the 21-gene recurrence score. PAM50-ROR provided more prognostic information than the recurrence score [32]. Although our study did not evaluate the standardized and clinically validated PAM50-ROR score, the GEICAM/9906 trial is an additional valuable source for biomarker comparisons. In the context of this trial, we could identify high-risk patients who need additional treatment to the standard anthracycline-based chemotherapy ( \pm taxane) and could be eligible for further treatment with novel drugs, such as CDK4/6 or mTOR inhibitors.

Our results should be interpreted in the context of its limitations. First, ROR scores were generated using research-based and non-standardized versions from qRTPCR platform. Although research-based PAM50 classification has been evaluated in several clinical trials using qRT-PCR [22, 33, 34], different methods may influence prognostic ability. Of note, large validation studies (ATAC and ABCSG8) for the PAM50 assay were performed using the standardized version with pre-specified cutoffs based on actual survival outcomes $(<10,10-20$, and $>20 \%$ risk of distant relapse at 10 years) and not subtype distribution [32]. Second, the PAM50 vs. EP comparison was not conducted according to their intended use. Whereas our patients were treated with chemotherapy, these predictors were clinically validated using patients cohorts receiving endocrine therapy alone. Therefore, next steps should compare PAM50 and EP in clinical trials with ER+l HER2 - BC patients treated with ET alone. EndoPredict and the standardized PAM50 were recently evaluated in the ABCSG8 trial, which would allow a direct comparison of both clinical predictors [35].

\section{Conclusions}

Despite the differences in establishment and the limited overlap in genes, all molecular predictors evaluated showed similar prognostic performance. The addition of clinical parameters, such as tumor size and nodal status, into risk-score determination improves the prognostic ability of these assays.

Author contributions MM, CP, PSB, KEW, RK, JCB, CMP, and AP participated in the conception and design of the study. MM, AR, LC, MRB, CAR, IMA, MAS, ARL, PBS, and RC contributed to the collection and assembly of data. MM, JCB, RK, RC, and MC participated in the analysis of the data. MM, JCB, RK, CP, PSB, KEW, $\mathrm{CMP}, \mathrm{AP}, \mathrm{EC}$, and $\mathrm{RC}$ participated in the interpretation of the data. $\mathrm{MM}, \mathrm{JCB}, \mathrm{CP}, \mathrm{RK}, \mathrm{CMP}, \mathrm{AP}, \mathrm{EC}$, and RC helped in the drafting of the manuscript. All authors contributed to the writing of the manuscript, read, and approved the final manuscript.

\section{Compliance with ethical standards}

Conflict of interest $\mathrm{CP}$ and RK are employees and shareholders of Sividon Diagnostics $\mathrm{GmbH}$ as well as inventors of EndoPredict patent applications. JCB and KEW were employees of Sividon Diagnostics $\mathrm{GmbH}$ at the time point of this study and both are inventors on the EndoPredict patent application. KEW is a shareholder of Sividon Diagnostics GmbH. CMP is a stockholder in Bioclassifier LLC, and an inventor on the PAM50 patent application. AP has an uncompensated advisory role for Nanostring Technologies. MM, EC, and $\mathrm{RC}$ are inventors on the PAM50 patent application. All remaining authors declare that they have no competing interest.

Informed consent All patients provided written informed consent to participate in the GEICAM/9906 trial and to perform molecular analysis on their breast tumors.

Research involving Human Participants All procedures performed in studies involving human participants were in accordance with the applicable legislation and the ethical standards of the institutional and/or national research committee and with the 1964 
Helsinki declaration and its later amendments or comparable ethical standards.

Open Access This article is distributed under the terms of the Creative Commons Attribution-NonCommercial 4.0 International License (http://creativecommons.org/licenses/by-nc/4.0/), which permits any noncommercial use, distribution, and reproduction in any medium, provided you give appropriate credit to the original author(s) and the source, provide a link to the Creative Commons license, and indicate if changes were made.

\section{References}

1. Prat A, Ellis MJ, Perou CM (2012) Practical implications of geneexpression-based assays for breast oncologists. Nat Rev Clin Oncol 9(1):48-57. doi:10.1038/nrclinonc.2011.178

2. Weigelt B, Reis-Filho JS, Swanton C (2012) Genomic analyses to select patients for adjuvant chemotherapy: trials and tribulations. Ann Oncol 23(Suppl 10):x211-x218. doi:10.1093/annonc/ mds 323

3. Paik S, Tang G, Shak S, Kim C, Baker J, Kim W, Cronin M, Baehner FL, Watson D, Bryant J, Costantino JP, Geyer CE Jr, Wickerham DL, Wolmark N (2006) Gene expression and benefit of chemotherapy in women with node-negative, estrogen receptor-positive breast cancer. J Clin Oncol 24(23):3726-3734. doi:10.1200/jco.2005.04.7985

4. Paik S, Shak S, Tang G, Kim C, Baker J, Cronin M, Baehner FL, Walker MG, Watson D, Park T, Hiller W, Fisher ER, Wickerham DL, Bryant J, Wolmark N (2004) A multigene assay to predict recurrence of tamoxifen-treated, node-negative breast cancer. N Engl J Med 351(27):2817-2826. doi:10.1056/NEJMoa041588

5. van't Veer LJ, Dai H, van de Vijver MJ, He YD, Hart AA, Mao M, Peterse HL, van der Kooy K, Marton MJ, Witteveen AT, Schreiber GJ, Kerkhoven RM, Roberts C, Linsley PS, Bernards R, Friend SH (2002) Gene expression profiling predicts clinical outcome of breast cancer. Nature 415(6871):530-536. doi:10. 1038/415530a

6. van de Vijver MJ, He YD, van't Veer LJ, Dai H, Hart AA, Voskuil DW, Schreiber GJ, Peterse JL, Roberts C, Marton MJ, Parrish M, Atsma D, Witteveen A, Glas A, Delahaye L, van der Velde T, Bartelink H, Rodenhuis S, Rutgers ET, Friend SH, Bernards R (2002) A gene-expression signature as a predictor of survival in breast cancer. N Engl J Med 347(25):1999-2009. doi:10.1056/NEJMoa021967

7. Buyse M, Loi S, van't Veer L, Viale G, Delorenzi M, Glas AM, d'Assignies MS, Bergh J, Lidereau R, Ellis P, Harris A, Bogaerts J, Therasse P, Floore A, Amakrane M, Piette F, Rutgers E, Sotiriou C, Cardoso F, Piccart MJ (2006) Validation and clinical utility of a 70-gene prognostic signature for women with nodenegative breast cancer. J Natl Cancer Inst 98(17):1183-1192. doi:10.1093/jnci/djj329

8. Albain KS, Barlow WE, Shak S, Hortobagyi GN, Livingston RB, Yeh IT, Ravdin P, Bugarini R, Baehner FL, Davidson NE, Sledge GW, Winer EP, Hudis C, Ingle JN, Perez EA, Pritchard KI, Shepherd L, Gralow JR, Yoshizawa C, Allred DC, Osborne CK, Hayes DF (2010) Prognostic and predictive value of the 21-gene recurrence score assay in postmenopausal women with nodepositive, oestrogen-receptor-positive breast cancer on chemotherapy: a retrospective analysis of a randomised trial. Lancet Oncol 11(1):55-65. doi:10.1016/s1470-2045(09)70314-6

9. Cuzick J, Dowsett M, Pineda S, Wale C, Salter J, Quinn E, Zabaglo L, Mallon E, Green AR, Ellis IO, Howell A, Buzdar AU, Forbes JF (2011) Prognostic value of a combined estrogen receptor, progesterone receptor, $\mathrm{Ki}-67$, and human epidermal growth factor receptor 2 immunohistochemical score and comparison with the Genomic Health recurrence score in early breast cancer. J Clin Oncol 29(32):4273-4278. doi:10.1200/jco.2010.31. 2835

10. Dowsett M, Cuzick J, Wale C, Forbes J, Mallon EA, Salter J, Quinn E, Dunbier A, Baum M, Buzdar A, Howell A, Bugarini R, Baehner FL, Shak S (2010) Prediction of risk of distant recurrence using the 21-gene recurrence score in node-negative and node-positive postmenopausal patients with breast cancer treated with anastrozole or tamoxifen: a TransATAC study. J Clin Oncol 28(11):1829-1834. doi:10.1200/jco.2009.24.4798

11. Albanell J, Gonzalez A, Ruiz-Borrego M, Alba E, Garcia-Saenz JA, Corominas JM, Burgues O, Furio V, Rojo A, Palacios J, Bermejo B, Martinez-Garcia M, Limon ML, Munoz AS, Martin M, Tusquets I, Rojo F, Colomer R, Faull I, Lluch A (2012) Prospective transGEICAM study of the impact of the 21-gene Recurrence Score assay and traditional clinicopathological factors on adjuvant clinical decision making in women with estrogen receptor-positive $(\mathrm{ER}+)$ node-negative breast cancer. Ann Oncol 23(3):625-631. doi:10.1093/annonc/mdr278

12. Geffen DB, Abu-Ghanem S, Sion-Vardy N, Braunstein R, Tokar M, Ariad S, Delgado B, Bayme M, Koretz M (2011) The impact of the 21-gene recurrence score assay on decision making about adjuvant chemotherapy in early-stage estrogen-receptor-positive breast cancer in an oncology practice with a unified treatment policy. Ann Oncol 22(11):2381-2386. doi:10.1093/annonc/ mdq769

13. Lo SS, Mumby PB, Norton J, Rychlik K, Smerage J, Kash J, Chew HK, Gaynor ER, Hayes DF, Epstein A, Albain KS (2010) Prospective multicenter study of the impact of the 21-gene recurrence score assay on medical oncologist and patient adjuvant breast cancer treatment selection. J Clin Oncol 28(10):1671-1676. doi:10.1200/jco.2008.20.2119

14. Dubsky P, Brase JC, Jakesz R, Rudas M, Singer CF, Greil R, Dietze O, Luisser I, Klug E, Sedivy R, Bachner M, Mayr D, Schmidt M, Gehrmann MC, Petry C, Weber KE, Fisch K, Kronenwett R, Gnant M, Filipits M (2013) The EndoPredict score provides prognostic information on late distant metastases in ER+/HER2 - breast cancer patients. $\mathrm{Br} \mathrm{J}$ Cancer 109(12):2959-2964. doi:10.1038/bjc.2013.671

15. Sestak I, Dowsett M, Zabaglo L, Lopez-Knowles E, Ferree S, Cowens JW, Cuzick J (2013) Factors predicting late recurrence for estrogen receptor-positive breast cancer. J Natl Cancer Inst 105(19):1504-1511. doi:10.1093/jnci/djt244

16. Kronenwett R, Bohmann K, Prinzler J, Sinn BV, Haufe F, Roth C, Averdick M, Ropers T, Windbergs C, Brase JC, Weber KE, Fisch K, Muller BM, Schmidt M, Filipits M, Dubsky P, Petry C, Dietel M, Denkert C (2012) Decentral gene expression analysis: analytical validation of the Endopredict genomic multianalyte breast cancer prognosis test. BMC Cancer 12:456. doi:10.1186/ 1471-2407-12-456

17. Denkert C, Kronenwett R, Schlake W, Bohmann K, Penzel R, Weber KE, Hofler H, Lehmann U, Schirmacher P, Specht K, Rudas M, Kreipe HH, Schraml P, Schlake G, Bago-Horvath Z, Tiecke F, Varga Z, Moch H, Schmidt M, Prinzler J, Kerjaschki D, Sinn BV, Muller BM, Filipits M, Petry C, Dietel M (2012) Decentral gene expression analysis for ER+/HER2- breast cancer: results of a proficiency testing program for the EndoPredict assay. Virchows Archiv 460(3):251-259. doi:10. 1007/s00428-012-1204-4

18. Filipits M, Rudas M, Jakesz R, Dubsky P, Fitzal F, Singer CF, Dietze O, Greil R, Jelen A, Sevelda P, Freibauer C, Muller V, Janicke F, Schmidt M, Kolbl H, Rody A, Kaufmann M, Schroth W, Brauch H, Schwab M, Fritz P, Weber KE, Feder IS, Hennig G, Kronenwett R, Gehrmann M, Gnant M (2011) A new 
molecular predictor of distant recurrence in ER-positive, HER2negative breast cancer adds independent information to conventional clinical risk factors. Clin Cancer Res 17(18):6012-6020. doi:10.1158/1078-0432.ccr-11-0926

19. Dubsky P, Filipits M, Jakesz R, Rudas M, Singer CF, Greil R, Dietze O, Luisser I, Klug E, Sedivy R, Bachner M, Mayr D, Schmidt M, Gehrmann MC, Petry C, Weber KE, Kronenwett R, Brase JC, Gnant M (2013) EndoPredict improves the prognostic classification derived from common clinical guidelines in ERpositive, HER2-negative early breast cancer. Ann Oncol 24(3):640-647. doi:10.1093/annonc/mds334

20. Parker JS, Mullins M, Cheang MC, Leung S, Voduc D, Vickery T, Davies S, Fauron C, He X, Hu Z, Quackenbush JF, Stijleman IJ, Palazzo J, Marron JS, Nobel AB, Mardis E, Nielsen TO, Ellis MJ, Perou CM, Bernard PS (2009) Supervised risk predictor of breast cancer based on intrinsic subtypes. J Clin Oncol 27(8):1160-1167. doi:10.1200/jco.2008.18.1370

21. Nielsen TO, Parker JS, Leung S, Voduc D, Ebbert M, Vickery T, Davies SR, Snider J, Stijleman IJ, Reed J, Cheang MC, Mardis ER, Perou CM, Bernard PS, Ellis MJ (2010) A comparison of PAM50 intrinsic subtyping with immunohistochemistry and clinical prognostic factors in tamoxifen-treated estrogen receptorpositive breast cancer. Clin Cancer Res 16(21):5222-5232. doi:10.1158/1078-0432.ccr-10-1282

22. Martin M, Prat A, Rodriguez-Lescure A, Caballero R, Ebbert MT, Munarriz B, Ruiz-Borrego M, Bastien RR, Crespo C, Davis C, Rodriguez CA, Lopez-Vega JM, Furio V, Garcia AM, Casas M, Ellis MJ, Berry DA, Pitcher BN, Harris L, Ruiz A, Winer E, Hudis C, Stijleman IJ, Tuck DP, Carrasco E, Perou CM, Bernard PS (2013) PAM50 proliferation score as a predictor of weekly paclitaxel benefit in breast cancer. Breast Cancer Res Treat 138(2):457-466. doi:10.1007/s10549-013-2416-2

23. Bastien RR, Rodriguez-Lescure A, Ebbert MT, Prat A, Munarriz B, Rowe L, Miller P, Ruiz-Borrego M, Anderson D, Lyons B, Alvarez I, Dowell T, Wall D, Segui MA, Barley L, Boucher KM, Alba E, Pappas L, Davis CA, Aranda I, Fauron C, Stijleman IJ, Palacios J, Anton A, Carrasco E, Caballero R, Ellis MJ, Nielsen TO, Perou CM, Astill M, Bernard PS, Martin M (2012) PAM50 breast cancer subtyping by RT-qPCR and concordance with standard clinical molecular markers. BMC Med Genomics 5:44. doi:10.1186/1755-8794-5-44

24. Prat A, Cheang MC, Martin M, Parker JS, Carrasco E, Caballero R, Tyldesley S, Gelmon K, Bernard PS, Nielsen TO, Perou CM (2013) Prognostic significance of progesterone receptor-positive tumor cells within immunohistochemically defined luminal A breast cancer. J Clin Oncol 31(2):203-209. doi:10.1200/jco.2012. 43.4134

25. Martin M, Brase JC, Calvo L, Krappmann K, Ruiz-Borrego M, Fisch K, Ruiz A, Weber KE, Munarriz B, Petry C, Rodriguez CA, Kronenwett R, Crespo C, Alba E, Carrasco E, Casas M, Caballero R, Rodriguez-Lescure A (2014) Clinical validation of the EndoPredict test in node-positive, chemotherapy-treated ER+/ HER2 - breast cancer patients: results from the GEICAM 9906 trial. Breast Cancer Res 16(2):R38. doi:10.1186/bcr3642

26. Martin M, Rodriguez-Lescure A, Ruiz A, Alba E, Calvo L, RuizBorrego M, Munarriz B, Rodriguez CA, Crespo C, de Alava E, Lopez Garcia-Asenjo JA, Guitian MD, Almenar S, GonzalezPalacios JF, Vera F, Palacios J, Ramos M, Gracia Marco JM, Lluch A, Alvarez I, Segui MA, Mayordomo JI, Anton A, Baena JM, Plazaola A, Modolell A, Pelegri A, Mel JR, Aranda E,
Adrover E, Alvarez JV, Garcia Puche JL, Sanchez-Rovira P, Gonzalez S, Lopez-Vega JM, Investigators GS (2008) Randomized phase 3 trial of fluorouracil, epirubicin, and cyclophosphamide alone or followed by Paclitaxel for early breast cancer. J Natl Cancer Inst 100(11):805-814. doi:10.1093/jnci/djn151

27. Muller BM, Kronenwett R, Hennig G, Euting H, Weber K, Bohmann K, Weichert W, Altmann G, Roth C, Winzer KJ, Kristiansen G, Petry C, Dietel M, Denkert C (2011) Quantitative determination of estrogen receptor, progesterone receptor, and HER2 mRNA in formalin-fixed paraffin-embedded tissue-a new option for predictive biomarker assessment in breast cancer. Diagn Mol Pathol B 20(1):1-10. doi:10.1097/PDM.0b013e3 181e3630c

28. Fan C, Prat A, Parker JS, Liu Y, Carey LA, Troester MA, Perou CM (2011) Building prognostic models for breast cancer patients using clinical variables and hundreds of gene expression signatures. BMC Med Genomics 4:3. doi:10.1186/1755-8794-4-3

29. Evaluation of Genomic Applications in Practice and Prevention (EGAPP) Working Group (2009) Recommendations from the EGAPP Working Group: can tumor gene expression profiling improve outcomes in patients with breast cancer? Genet Med 11(1):66-73. doi:10.1097/GIM.0b013e3181928f56

30. Fan C, Oh DS, Wessels L, Weigelt B, Nuyten DS, Nobel AB, van't Veer LJ, Perou CM (2006) Concordance among gene-expression-based predictors for breast cancer. N Engl J Med 355(6):560-569. doi:10.1056/NEJMoa052933

31. Haibe-Kains B, Desmedt C, Piette F, Buyse M, Cardoso F, Van't Veer L, Piccart M, Bontempi G, Sotiriou C (2008) Comparison of prognostic gene expression signatures for breast cancer. BMC Genom 9:394. doi:10.1186/1471-2164-9-394

32. Dowsett M, Sestak I, Lopez-Knowles E, Sidhu K, Dunbier AK, Cowens JW, Ferree S, Storhoff J, Schaper C, Cuzick J (2013) Comparison of PAM50 risk of recurrence score with oncotype DX and IHC4 for predicting risk of distant recurrence after endocrine therapy. J Clin Oncol 31(22):2783-2790. doi:10.1200/ jco.2012.46.1558

33. Cheang MC, Voduc KD, Tu D, Jiang S, Leung S, Chia SK, Shepherd LE, Levine MN, Pritchard KI, Davies S, Stijleman IJ, Davis C, Ebbert MT, Parker JS, Ellis MJ, Bernard PS, Perou CM, Nielsen TO (2012) Responsiveness of intrinsic subtypes to adjuvant anthracycline substitution in the NCIC.CTG MA.5 randomized trial. Clin Cancer Res 18(8):2402-2412. doi:10.1158/ 1078-0432.ccr-11-2956

34. Chia SK, Bramwell VH, Tu D, Shepherd LE, Jiang S, Vickery T, Mardis E, Leung S, Ung K, Pritchard KI, Parker JS, Bernard PS, Perou CM, Ellis MJ, Nielsen TO (2012) A 50-gene intrinsic subtype classifier for prognosis and prediction of benefit from adjuvant tamoxifen. Clin Cancer Res 18(16):4465-4472. doi:10. 1158/1078-0432.ccr-12-0286

35. Gnant M, Filipits M, Greil R, Stoeger H, Rudas M, Bago-Horvath Z, Mlineritsch B, Kwasny W, Knauer M, Singer C, Jakesz R, Dubsky P, Fitzal F, Bartsch R, Steger G, Balic M, Ressler S, Cowens JW, Storhoff J, Ferree S, Schaper C, Liu S, Fesl C, Nielsen TO (2014) Predicting distant recurrence in receptorpositive breast cancer patients with limited clinicopathological risk: using the PAM50 risk of recurrence score in 1478 postmenopausal patients of the ABCSG-8 trial treated with adjuvant endocrine therapy alone. Ann Oncol 25(2):339-345. doi:10.1093/ annonc/mdt494 